\title{
Modifying speed of group decision making without awareness of group members'
}

\author{
W. D. JOSLYY, UNIVERSITY OF WISCONSIN \\ THOMAS J. BANTA, UNIVERSITY OF CINCINNATI
}

Contingent reinforcement successfully modified speed of decision making by two-person groups. Depending on the reinforcement contingency, groups either increased or decreased decision time relative to control groups given noncontingent reinforcement on matching schedules. As far as could be determined from post-experimental questionnaires and interviews, none of the $S$ s had insight into the reinforcement contingency. The results suggest that the basic operant conditioning paradigm may be applicable to the modification of interdependent behavior patterns in free-responding groups even though the members of the group are unaware that they are adjusting their interaction patterns to fit the external situation.

Verbal conditioning studies such as those initiated by Greenspoon (1955) and reviewed by Krasner (1958) have demonstrated that the behavior of a single $S$ may be modified by contingent reinforcement without patent awareness on the part of the S. Banta \& Nelson (1964) and Banta \& Horowitz (1964) have shown that interdependent behavior patterns in groups can be modified by contingent reinforcement. In the latter experiments no attempt was made to prevent the Ss knowing which types of group interactions were being rewarded. The present study attempts to bridge the gap between these two types of experiments, i.e., to modify group processes by contingent reinforcement without awareness of group members that their behavior is being changed.

Method

Thirty female pairs of Ss, volunteers from introductory psychology classes at the University of Wisconsin, served as Ss. The members of each pair, strangers to each other, were seated at a table and faced a one-way mirror. A response panel was on the table. The Ss job was to discuss and jointly predict the response of a "third person" to an attitude test on the basis of their knowledge of his first five answers alone. Ss indicated their joint decisions on the response panel by flipping a switch under one of the six alternative labels located at the top of the panel: Strongly Agree, Agree, Slightly Agree, flightly Disagree, Disagree, and Strongly Disagree. There were 45 such decisions for each of three consecutive daily sessions, and each decision constituted an experimental trial. Reinforcement was administered through a panel of lights that indicated whether the decision reached by the pair was correct or incorrect.

Each pair of Ss was assigned to one of four treatment groups: one reinforced for long decision time, one reinforced for short decision time, and a control group for each of the experimental groups. Long decision time was defined as longer than the median number of seconds required to complete the previous three trials; short decision time was shorter than the median decision time for the previous three trials. Experimental pairs were assigned to the appropriate reinforcement condition on the basis of their decision time during the initial 15 trials of the first session (operant level). During these 15 operant trials all pairs of Ss were given non-contingent reinforcement. Pairs with high operant levels were given positive reinforcement for short decision time, while those with low operant levels were assigned to groups reinforced for long decision time. Each control pair was given a reinforcement schedule identical to that received by the matched experimental pair. Control pairs received positive (or negative) reinforcement on a given trial according to the predetermined schedule, regardless of their decision time.

Immediately following the third experimental session each $\mathrm{S}$ was administered a written questionnaire and then interviewed individually by the experimenter to reveal any insights Ss may have had into the reinforcement contingency.

Details of experimental and observational procedures are given in Banta \& Nelson (1964), Banta (1963), and for this experiment in particular, in Joslyn (1964). Results

The data were normalized by a log transformation. A 2 by 2 by 3 by 2 analysis of variance for repeated measures was computed. Figure 1 represents mean decision time per trial for each of the nine 15-trial blocks. Contingent reinforcement was effective in both increasing and decreasing decision time. This was reflected by the operant level by treatment by sessions interaction $(F=4.32, \mathrm{df}=2 / 26, \mathrm{p}<.025)$. By the end of the second experimental session maximal separation between experimental and control groups in the predicted direction had been achieved; this separation was maintained but not increased during the third session. Both experimental groups diverged from their respective control groups in the non-predicted direction during the first session, but this temporary trend was not significant $(\mathrm{F}<1.0)$.

Two secondary trends were observed in the data. First, decision time decreased within each session $(p<.05)$ and between sessions $(p<.001)$. Second, pairs which began with high operant levels maintained relatively longer decision time throughout the experiment than pairs which began with low operantlevels $(p<.025)$. 


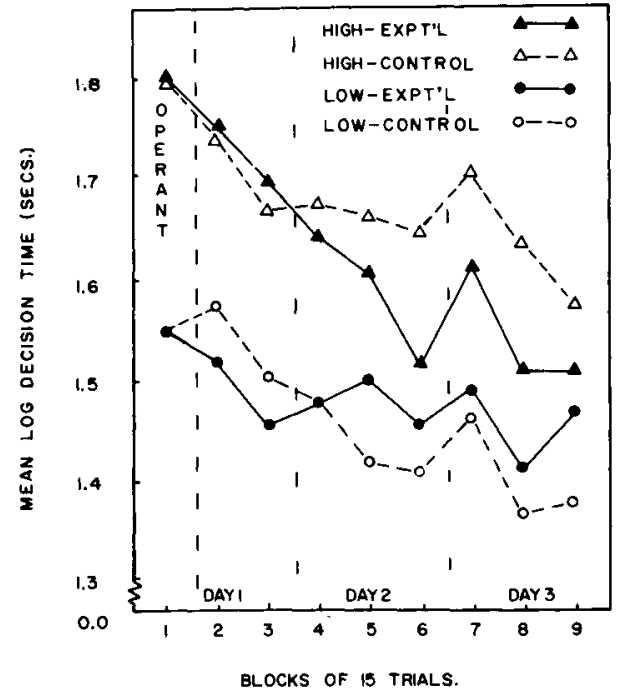

Fig. 1. Mean $\log$ decision time in seconds as a function of contingent reinforcement (high and low experimental groups) and of non-contingent reinforcement (high and low control groups).

This consistency in the behavior of pairs of Ss was also supported by an average correlation of $+.67(p<.01)$ between operant level decision time and subsequent decision time throughout the experiment.

In response to the post-experimental question, "Describe in your own words what you think this whole experiment was about. What is your impression of the purpose of this experiment?," 41 Ss thought the purpose was to predict a person's attitudes on the basis of limited information. Other hypotheses entertained by the Ss were that $E$ was studying such processes as dominance, compromise, leadership cooperation, role playing, memory, stereotypes, and problem solving. Ss were also asked to recall whether a lot of discussion resulted in more or fewer correct predictions during the first, second, and third sessions. Most Ss believed that a lot of discussion resulted in more correct predictions during all three sessions whether they had been reinforced for long decision time or for short decision time (first session, $p<.01$; second session, $p<.01$; third session, $p<.05$ ). The percentage of Ss in the group reinforced for long decision time correctly holding this belief was as follows: first session, 100\%; second session, $86 \%$; third session, $75 \%$. The percentage of Ss reinforced for short decision time incorrectly holding this belief was as follows: first session, $94 \%$; second session, $69 \%$; third session, $62 \%$. When the responses of the two groups were compared by $\mathrm{X}^{2}$ tests, $p^{\prime}$ 's were greater than .50 for each session. The fact that this belief was not a function of Ss history of reinforcement further supports the hypothesis that the Ss were unaware.

\section{Discussion}

Three identifiable factors influenced decision time: (1) operant level, (2) a trend toward more rapid decisions by all pairs as they went through the experiment, and (3) contingent reinforcement. It is, of course, this third factor which was of primary interest, and its effect was superimposed upon that of the first two factors.

Reinforcement for short decision time facilitated the trend for all pairs to decrease decision time as the experiment progressed. Reinforcement for long decision time opposed this trend and its effect was to maintain the decision time of the low operant experimental group at a constant level while the low operant control group decreased.

The trend toward more rapid decisions within problem solving sessions identical to those used in the present study was observed by Probasco and Banta (personal communication, 1962) and by Horowitz (1963). The present study found that this decrease continued through three consecutive daily sessions. Horowitz has suggested (1963) that this tendency may be attributable to a progressive routinization of communication patterns throughout the experiment.

What has been demonstrated in the present experiment is that social behavior can be modified by external contingencies which bear a very subtle relationship to the behavior being changed.

\section{Reterences}

Banta, T. J. Aggregate reinforcement of free social interaction. Paper read at the Wisconsin Conference on Experimental Analyses of Social Interaction, August 19-23, 1963, Madison, Wisconsin.

Banta, T. J., \& Horowitz, H. Resource location in problem solving groups made up of married couples, friends, and strangers. Psychon. Sci., 1964, 1, 339-340.

Banta, T. J., \& Nelson, C. Experimental analysis of resource location in problem solving groups. Sociometry, 1964, 27, 488-501.

Greenspoon, J. The reinforcing effect of two spoken sounds on the frequency of two responses. Amer. J. Psychol., 1955, 68, 409416.

Horowitz, H. Random reinforcement of group decisions and its effects upon verbal behavior in dyads. Unpublished master's thesis, University of Wisconsin, 1964.

Krasner, L. Studies of the conditioning of verbal behavior. Psychol. Bull., 1958, 55, 148-170.

\section{Note}

1. This research was supported by Grant MH06033-2 provided by the National Institute of Mental Health. Appreciation is expressed to Dr. C. Michael Levy for his suggestions concenring the experimental design and to Dr. Harold J. Fletcher, Dr. David A. Grant, and Dr. David W. Bessemer for their advice concerning the statistical treatment of the data. Thanks are due to Dr. Carnot Nelson for his essential part in the data collection. The apparatus used in this experiment was made and donated by the Wisconsin Telephone Company. This major contribution to our research program was much appreciated. 